\title{
BMJ Open Continuum of maternal healthcare services utilisation and associated factors among women who gave birth in Siyadebirena Wayu district, Ethiopia: community-based cross-sectional study
}

$\overline{\text { Seblewongel Gebretsadik Sertsewold, }{ }^{1} \text { Ayal Debie (1) , }{ }^{2} \text { Demiss Mulatu Geberu (D) }{ }^{2}}$

To cite: Sertsewold SG, Debie A Geberu DM. Continuum of maternal healthcare services utilisation and associated factors among women who gave birth in Siyadebirena Wayu district, Ethiopia: community-based cross-sectional study. BMJ Open 2021;11:e051148. doi:10.1136/ bmjopen-2021-051148

- Prepublication history and additional supplemental material for this paper are available online. To view these files, please visit the journal online (http://dx.doi.org/10.1136/ bmjopen-2021-051148).

Received 10 March 2021 Accepted 29 0ctober 2021

D) Check for updates

C Author(s) (or their employer(s)) 2021. Re-use permitted under CC BY-NC. No commercial re-use. See rights and permissions. Published by BMJ.

${ }^{1}$ Department of Public Health, School of Public Health, College of Medicine and Health Sciences, Dilla University, Dilla, Ethiopia

${ }^{2}$ Department of Health Systems and Policy, Institute of Public Health, College of Medicine and Health Sciences, University of Gondar, Gondar, Ethiopia

\section{Correspondence to} Demiss Mulatu Geberu; mulatu.demissma23@gmail. com

\section{ABSTRACT}

Objective This study aimed to analyse the prevalence and factors associated with continuum of maternal healthcare services among women who gave birth in Siyadebirena Wayu district, Central Ethiopia.

Design Community-based cross-sectional study. Setting At eight Kebeles in Central Ethiopia.

Participants The study was done on 614women aged 15-49 years using interviewer-administered structured questionnaire. Following proportional allocation of the sample, we used simple random sampling technique to select study participants.

Methods Binary logistic regression model was fitted to identify the factors associated with the outcome. Variables with $p<0.2$ in the bivariable analysis were the candidates for multivariable analysis. $A p<0.05$ and adjusted $O R$ (AOR) with $95 \% \mathrm{Cl}$ were taken to declare the factors and the strengths of association with continuum of maternal healthcare utilisation.

Outcome Continuum of maternal healthcare utilisation. Results Only $16.1 \%$ (95\% Cl $13.3 \%$ to $19.0 \%$ ) of the women had used a complete continuum of maternal health services. Variables, such as contraceptive use (AOR 4.95; 95\% Cl 1.61 to 15.20 ), autonomy (AOR $4.45 ; 95 \% \mathrm{Cl} 1.69$ to 11.60 ), urban residence (AOR 3.91; $95 \% \mathrm{Cl} 1.06$ to 14.39), educated women (AOR 5.36; $95 \% \mathrm{Cl} 1.15$ to 25.06), took less than $30 \mathrm{~min}$ to reach a health facility (AOR $3.17 ; 95 \% \mathrm{Cl} 1.38$ to 7.25 ), use public transportation (AOR 2.48; $95 \% \mathrm{Cl} 1.12$ to 5.52 ) and good knowledge (AOR 9.88; $95 \% \mathrm{Cl} 3.89$ to 25.0 ) were positively associated with continuum of maternal healthcare. In the contrary, women who had third child birth order (AOR 0.22; $95 \% \mathrm{Cl} 0.06$ to 0.8 ) was negatively associated.

Conclusions Overall, the level of the continuum of maternal healthcare services utilisation was low compared with the national and global targets. Therefore, programme planners and implementer had better conduct health education to enhance the awareness of women about continuum of maternal healthcare services. Healthcare sector policy-makers and managers shall also scale up healthcare facilities to improve access to maternal healthcare services.

\section{INTRODUCTION}

Continuum of maternal healthcare is the continuity of care for maternal and child
Strengths and limitations of this study

- The continuity of key maternal healthcare service utilisation can be mentioned as the strengths of this study.

- This study might introduce social desirability bias, which results in overestimation of the results associated with self-reported data.

- Recall bias could also be another limitation since mothers were interviewed to respond to questions about their last 12 months pregnancy-related experiences.

- This study did not explore non-quantifiable judgments/perception of mothers since it lacked a qualitative aspect.

healthcare services, which includes antenatal care (ANC), skilled birth attendance and postnatal care (PNC) services to reduce maternal and neonatal morbidity and mortality. ${ }^{1}$ Improving maternal health was one of the eight Millennium Development Goals (MDGs) to reduce the maternal mortality ratio (MMR) by three quarters and to realise universal access to reproductive health by $2015 .^{2}$ To realise the remaining business of MDGs, all United Nations (UN) member states had set an ambitious sustainable development goal (SDG) to reduce MMR to less than 70 per 100000 births in 2030. ${ }^{3}$ Alongside, the expected reduction of MMR to realise the SDG targets was $6.4 \%$ per year, but it was only $2.9 \% .^{24}$

Although the global MMR has declined by $38 \%$ from 2000 to 2017 , over 800 women are dying each day from causes associated with obstetric complications in low-income and middle-income countries. ${ }^{2}{ }^{5}$ Of which, approximately 550 maternal deaths reported every day in sub-Saharan African (SSA) countries account $66 \%$ of the total deaths. ${ }^{6}$ 
Table 1 Sociodemographic data of participants in Siyadebirena Wayu district, central Ethiopia, $2020(\mathrm{n}=614)$

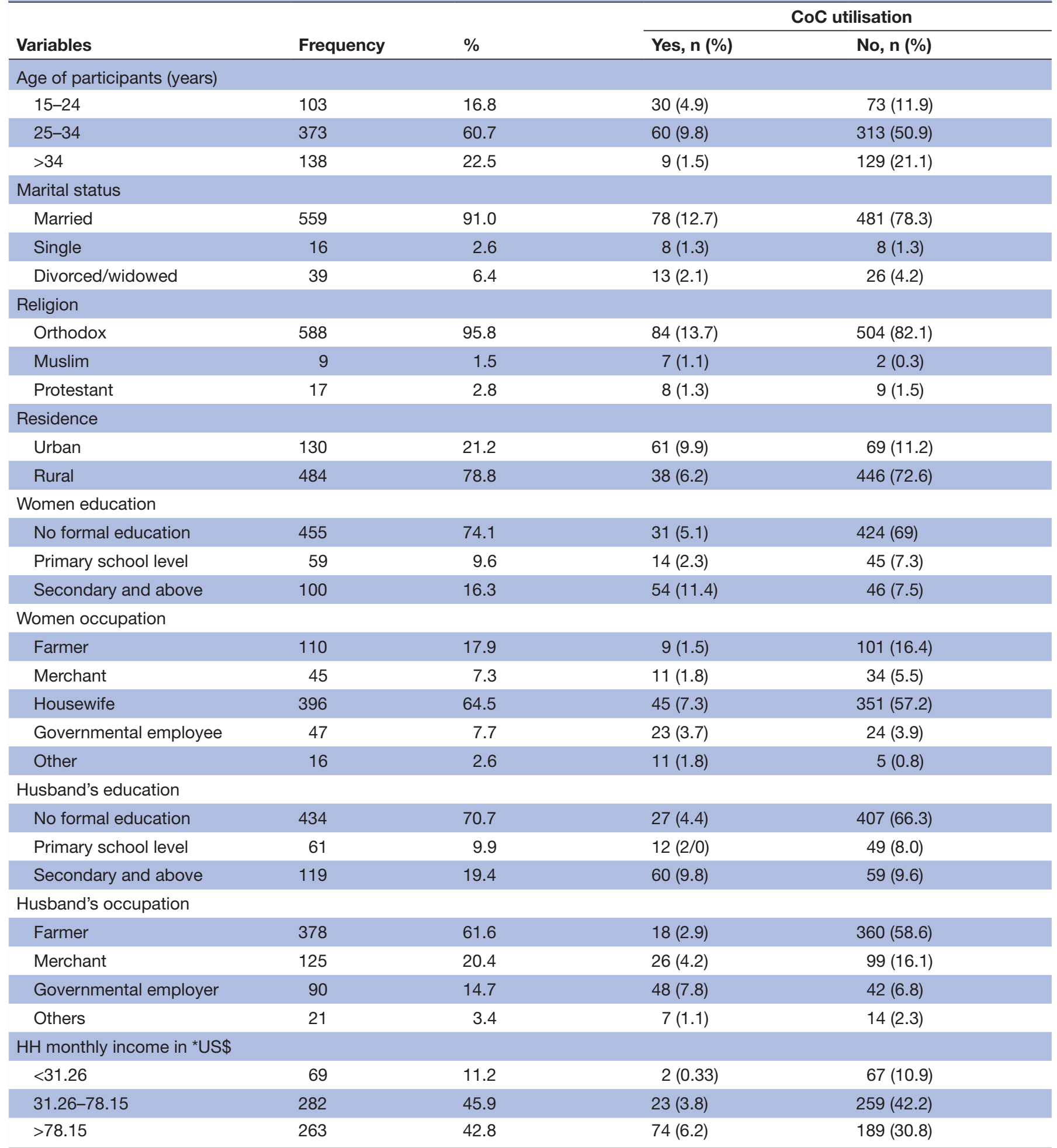

*US\$1=ETB 31.99 in February 2020.

$\mathrm{CoC}$, continuum of care; $\mathrm{HH}$, household.

Similarly, MMR in Ethiopia was 412 deaths per 100000 live births in 2016. ${ }^{1}$ Moreover, more than 10 million children died globally before their fifth years birth day from preventable and treatable childhood illness. ${ }^{78}$ However, most of the maternal and child deaths that are related with pregnancy and childbirth complications are preventable and/or treatable. ${ }^{39}$

Continuum of care (COC) has recently been highlighted as a core principle of programmers to reduce the high burden of maternal, neonatal and child deaths. ${ }^{10}$ 
Table 2 Health service accessibility and autonomy related data of participants in Siyadebirena Wayu district, central Ethiopia, $2020(n=614)$

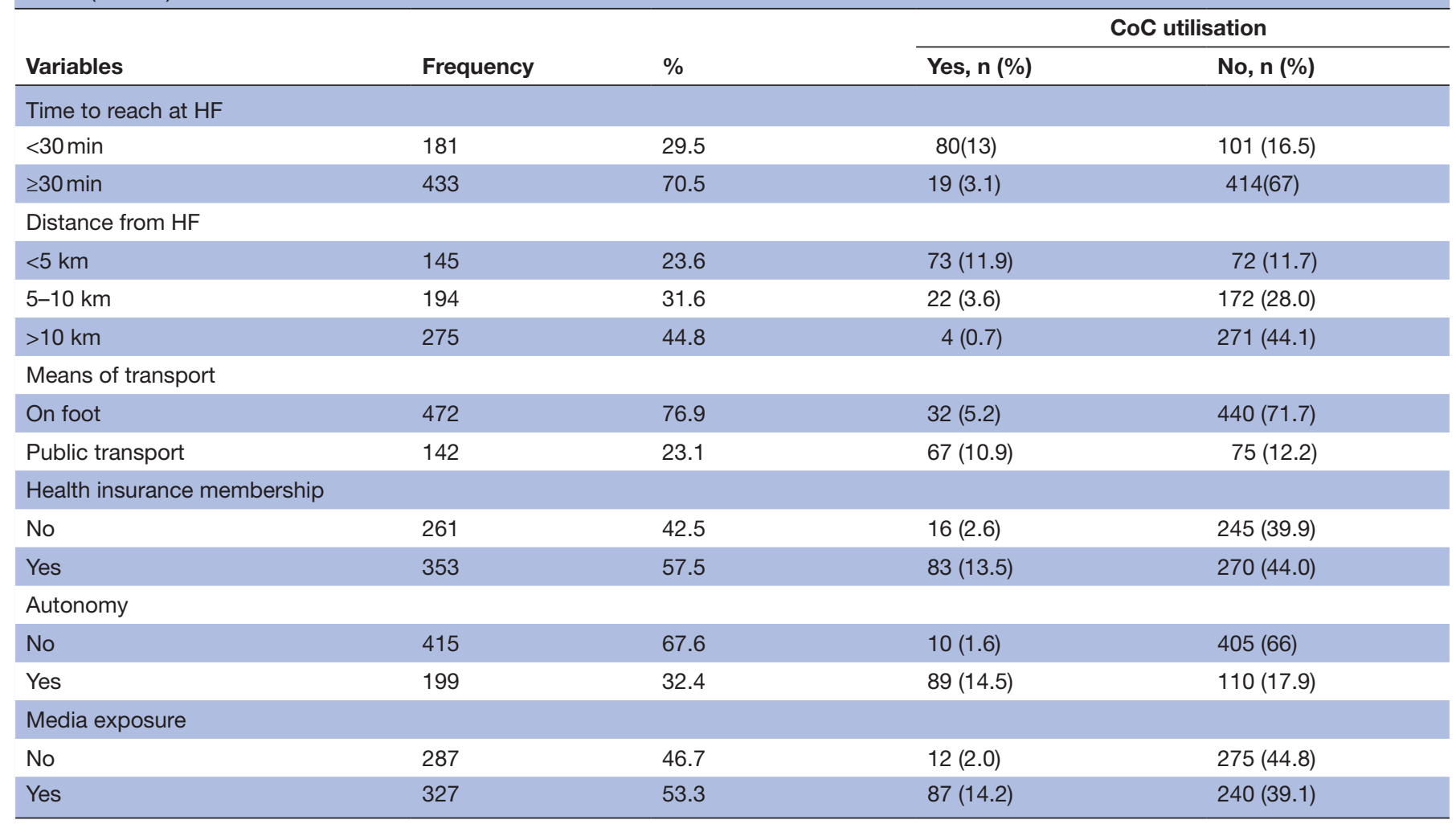

CoC, continuum of care; HF, Health Facility.

Maternal, newborn and child healthcare services are inseparably linked and should be managed in an integrated way. In accordance with this, four prenatal care visits, skilled birth attendance and PNC, especially within the first 48 hours after births is recommended to manage postpartum haemorrhage and other causes of maternal and neonatal mortality. ${ }^{9}$ Studies done in Pakistan, Laos and Nepal indicated that only $6.8 \%-45.7 \%$ women received complete maternal healthcare services. ${ }^{4} 1112$ Studies conducted in Kenya, Ghana and Tanzania also showed that only $8.0 \%-34.0 \%$ of women used the recommended full range of maternal health services. ${ }^{13-15}$ More than $86 \%$ of mothers in SSA including Ethiopia did not also use complete maternal healthcare services. ${ }^{16-18}$

A few available evidences in Africa also indicated that maternal education, occupation, decision-making autonomy, transportation access, use of contraception and previous birth place were the major contributing factors for utilisation of maternal healthcare service. ${ }^{1317-19}$ Many countries including Ethiopia have implemented free service packages for maternal healthcare services to reduce the financial burden and to facilitate the realisation of Universal Health Coverage. ${ }^{20-22}$ The progress of maternal health services utilisation, however, was insignificant. ${ }^{23}$ Successful programme implementation to improve the COC relies on a better understanding of where the gaps are seeking care. ${ }^{24}$
Although COC is one of the key programme strategies to improve maternal and newborns health and to realise SDG, it was not well investigated in Ethiopia. Therefore, this study aimed to assess the level of continuum of maternal healthcare and associated factors in Siyadebirena Wayu district, Central Ethiopia.

\section{MATERIALS AND METHODS Study design and setting}

A community-based cross-sectional study was conducted from 1 February 2020 to 10 March 2020 in Siyadebirena Wayu district which is located in Central Ethiopia. This district borders surrounded by the Oromia Region in the South, Ensaro in the West, Moretna Jiru in the North, and Basona Werana in the East. Based on the 2007 national census conducted by the Central Statistical Agency of Ethiopia, this district has a total population of 61,046, of whom, 31322 were men and $7.41 \%$ were urban inhabitants. ${ }^{25}$ There are one urban and thirteen rural kebeles in the district. There are 18 healthcare facilities: 1 primary hospital, 3 health centres and 14 health posts that provide outpatient service, inpatient service and maternal health service to their catchment population. ${ }^{26}$

\section{Population}

All reproductive age women (15-49 years) in Siyadebirena Wayu district who gave birth 1 year ago from 
Table 3 Perceived quality of care related data of participants in Siyadebirena Wayu district, central Ethiopia, $2020(n=614)$

\begin{tabular}{|c|c|c|}
\hline Variables & Frequency & $\%$ \\
\hline \multicolumn{3}{|c|}{ Perception on availability of adequate rooms } \\
\hline No & 23 & 3.7 \\
\hline Yes & 591 & 96.3 \\
\hline \multicolumn{3}{|c|}{ Perception on availability of health professionals } \\
\hline No & 603 & 98.2 \\
\hline Yes & 11 & 1.8 \\
\hline \multicolumn{3}{|c|}{ Perception on availability of drugs } \\
\hline No & 399 & 65 \\
\hline Yes & 215 & 35 \\
\hline
\end{tabular}

Perception on availability of medical equipment

$\begin{array}{ccc}\text { No } & 340 & 55.4 \\ \text { Yes } & 274 & 44.6 \\ \begin{array}{l}\text { Perception on health professionals ensured } \\ \text { examination }\end{array} & \\ \text { No } & 20 & 3.3 \\ \text { Yes } & 594 & 96.7\end{array}$

Perception on health professional's willingness to help

$\begin{array}{lll}\text { No } & 330 & 53.7 \\ \text { Yes } & 284 & 46.3\end{array}$

Perception on health professionals respecting of patients

$\begin{array}{lll}\text { No } & 334 & 54.4 \\ \text { Yes } & 280 & 45.6\end{array}$

Perception on health professionals were examining well

$\begin{array}{lll}\text { No } & 214 & 34.9 \\ \text { Yes } & 400 & 65.1\end{array}$

Perception on health professionals were welcoming well

$\begin{array}{lll}\text { No } & 334 & 54.4 \\ \text { Yes } & 280 & 45.6\end{array}$

Perception on geting adequate information about patient's health status

\begin{tabular}{|c|c|c|}
\hline No & 22 & 3.6 \\
\hline Yes & 592 & 96.4 \\
\hline \multicolumn{3}{|c|}{ Perception on the health facilities were well cleaned } \\
\hline No & 310 & 50.5 \\
\hline Yes & 304 & 49.5 \\
\hline \multicolumn{3}{|c|}{ Perceived quality of maternal healthcare services } \\
\hline Poor & 351 & 57.2 \\
\hline Good & 263 & 42.8 \\
\hline
\end{tabular}

the data collection period were the source population while those women in the selected kebeles of the district were the study population. Those seriously ill women and women who lived less than 6 months in the district during the data collection period were excluded from the study.

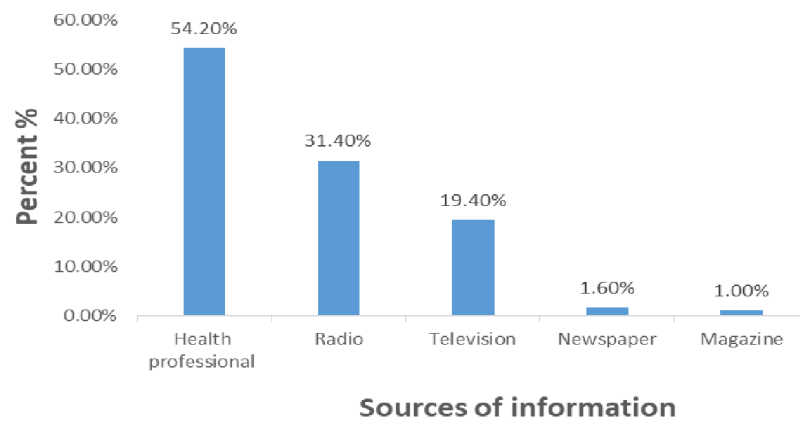

Figure 1 Source of information about maternal health of participants in Siyadebirena Wayu district, central Ethiopia, 2020.

\section{Sample size and sampling procedure}

The sample size was determined using single population proportion formula: $\mathrm{n}=\frac{(\mathrm{Za} / 2)^{2} \mathrm{P}(1-\mathrm{P})}{\mathrm{d}^{2}}$. Proportion $(\mathrm{p}=9.7 \%)$ of mothers had continuum of maternal healthcare service utilisation in Arbaminch, Ethiopia ${ }^{18}$; $3 \%$ margin of error; $95 \%$ confidence level at $\mathrm{Z} \alpha / 2$ $(\alpha=0.05)=1.96 ; 10 \%$ non-response rate and 1.5 design effect were considered for sample size determination. As a result, the final sample size was 620 .

In the study area, there are one urban and thirteen rural Kebeles. After stratifying into urban and rural areas, 1 and 7 sample kebeles were drawn from urban and rural kebele in the district, respectively, by lottery method (simple random sampling). We used the lists of all eligible women including mothers who gave birth at home from the health posts' community health information system (CHIS) maternal data on women who gave births from January 2019 to January 2020. In order not to miss women who gave birth at home or those who delivered at health facility but not found in that selected kebeles, health development army leaders were used to identify those mothers in each selected kebeles. Then, simple random sampling technique was used to select the participants after proportional allocation of women to each selected kebele had been made.

\section{Variables}

Continuum of maternal healthcare utilisation was the dependent variable. The independent variables included sociodemographic factors (women's age, marital status, women's educational status, husband's educational status, women's employment status, husband's employment status, religion, residence and monthly income), health service accessibility-related factors (membership of health insurance, perceived required time to reach a health facility, perceived distance from the health facility, perceived quality of care, media exposure, autonomy and means of transport), obstetric characteristics (ANC initiation, history of contraceptive use, desire for pregnancy, and birth order), and women's knowledge-related factors (knowledge towards maternal healthcare and attitude towards maternal healthcare). 
Table 4 Knowledge of participants in Siyadebirena Wayu district, central Ethiopia, $2020(n=614)$

\begin{tabular}{lcc}
\hline Variables & \multicolumn{1}{c}{ Frequency } & $\%$ \\
\hline \multicolumn{2}{l}{ Does antenatal care is needed? } & \\
No & 59 & 9.6 \\
Yes & 555 & 90.4 \\
Should antenatal care examination be started & within 4 months? \\
No & 521 & 84.9 \\
Yes & 93 & 15.1 \\
Is it needed to count fetal movement in the late stage of pregnancy? \\
No & 536 & 87.3 \\
Yes & 78 & 12.7
\end{tabular}

Can anaemia prevent through eating more iron contained food during pregnancy?

\begin{tabular}{|ccc|} 
No & 541 & 88.1 \\
\hline Yes & 73 & 11.9 \\
Is there a difference between & giving birth at home and health \\
facility? & & \\
\hline No & 606 & 1.3 \\
\hline Yes & 527 & 98.7 \\
\hline Should pregnant women often check blood pressure? \\
No & 87 & 85.8 \\
\hline Yes & 14.2 \\
\hline Did you think keep lying is better when amniotic fluid breaks? \\
\hline No & 557 & 90.7 \\
\hline Yes & 57 & 9.3
\end{tabular}

Is it needed to go to hospital when severe headache happens?

$\begin{array}{lrr}\text { No } & 13 & 2.1 \\ \text { Yes } & 601 & 97.9\end{array}$

Is it needed to go to hospital when vision problem happens?

$\begin{array}{lrr}\text { No } & 2 & 0.3 \\ \text { Yes } & 612 & 99.7\end{array}$

Did you think breast feeding is better for newborn?

$\begin{array}{lll}\text { No } & 168 & 27.4 \\ \text { Yes } & 446 & 72.6\end{array}$

Did you think newborn deformity most likely occur before 12 weeks of pregnancy?

$\begin{array}{lrr}\text { No } & 578 & 94.1 \\ \text { Yes } & 36 & 5.9\end{array}$

Did you think vaccination for new born baby is important?

\begin{tabular}{ccr} 
No & 32 & 5.2 \\
Yes & 582 & 94.8 \\
Overall knowledge about & maternal health services \\
Poor & 500 & 81.4 \\
Good & 114 & 18.6 \\
\hline
\end{tabular}

\section{Operational definitions}

Continuum of maternal healthcare utilisation was assumed to be completed if a woman had at least four prenatal care visits, skilled delivery, and at least one PNC visit within 6 weeks by skilled health workers. ${ }^{141819}$ 27-29
Table 5 Attitude of participants towards maternal healthcare services in Siyadebirena Wayu district, central Ethiopia, $2020(n=614)$

Variables $\quad$ Frequency $\%$

I would like to attend antenatal care as required.

$\begin{array}{lrr}\text { No } & 42 & 6.8 \\ \text { Yes } & 572 & 93.2\end{array}$

I preferred to give birth at health facility for my next delivery.

$\begin{array}{lrr}\text { No } & 9 & 1.5 \\ \text { Yes } & 605 & 98.5\end{array}$

I Would like to get instruction of infant feeding from health worker.

$\begin{array}{lll}\text { No } & 500 & 81.4 \\ \text { Yes } & 114 & 18.6\end{array}$

I Would like to be visited by health worker during postpartum period.

\begin{tabular}{ccc} 
No & 544 & 88.6 \\
Yes & 70 & 11.4 \\
I would like to breastfeed & & \\
No & 30 & 4.9 \\
Yes & 584 & 95.1 \\
I would you like to return to work & 539 & 87.8 \\
No & 75 & 12.2 \\
Yes & 486 & 79.2 \\
Overall attitude towards & maternal health services \\
Poor & 128 & 20.8 \\
\hline Good & &
\end{tabular}

Knowledge about maternal healthcare was measured by using 12 knowledge measuring items. Accordingly, each item contains (' $1=$ yes' and ' $0=$ no' alternatives) and those women who scored above $50 \%$ of the total knowledge measuring score were considered as having good knowledge. $^{29}$ Attitude towards maternal healthcare was measured using six attitude measuring items, each containing a five point Likert scale ( $1=$ strongly disagree, $2=$ disagree, $3=$ neutral, $4=$ agree and $5=$ strongly agree) and those women who scored above $75 \%$ of the total attitude measuring scores were considered as having a favourable attitude. ${ }^{29}$ Media exposure of the women was considered if they had a chance of getting maternal health-related information from any source, such as radio, television (TV), magazine, health professionals, etc. ${ }^{30}$ Perceived quality of maternal healthcare of the women was measured by using 11-item questions, each containing a five point Likert scale ( $1=$ strongly disagree, $2=$ disagree, $3=$ neutral, $4=$ agree and $5=$ strongly agree), and those women who scored over $75 \%$ of the total quality perception measuring score were considered as having good perception. ${ }^{31} \mathrm{~A}$ woman was considered as having decision-making autonomy if she had a power to decide for healthcare needs by herself or with her husband. ${ }^{18}$ 
Table 6 Obstetrics characteristics of participants in Siyadebirena Wayu district, central Ethiopia, $2020(n=614)$

\begin{tabular}{|c|c|c|c|c|}
\hline \multirow[b]{2}{*}{ Variables } & \multirow[b]{2}{*}{ Frequency } & \multirow[b]{2}{*}{$\%$} & \multicolumn{2}{|c|}{ CoC utilisation } \\
\hline & & & Yes, n (\%) & No, n (\%) \\
\hline \multicolumn{5}{|c|}{ Contraceptive use } \\
\hline Yes & 389 & 63.4 & $93(15.1)$ & $296(48.2)$ \\
\hline \multicolumn{5}{|c|}{ Pregnancy desire } \\
\hline Planned & 394 & 64.2 & 83 (13.5) & $311(50.7)$ \\
\hline \multicolumn{5}{|c|}{ Order of baby } \\
\hline 1 & 65 & 10.6 & $24(3.9)$ & $41(6.7)$ \\
\hline 2 & 137 & 22.3 & $40(6.5 \%)$ & $97(15.8)$ \\
\hline 3 & 179 & 29.2 & $21(3.4)$ & $158(25.7)$ \\
\hline$\geq 4$ months & 263 & 42.8 & $52(14.5)$ & 211 (58.9) \\
\hline
\end{tabular}

ANC, antenatal care; GA, gestational age.

\section{Data collection tool and procedures}

A structured interviewer administered questionnaire was developed through reviewing previous literatures $^{14161829-34}$ (online supplemental file 1). The questionnaire was prepared in English and translated to Amharic and back to English to maintain its consistency. The English language questionnaire was translated into the Amharic language by the authors of this research with the help of a language expert. The back-translation of the Amharic version was performed by senior academic staff of the Department of Health Systems and Policy who were not members of the research group and had no information about the original questionnaire. Then, the authors, the language expert and the senior academic staff members met and discussed the translation and back-translation. Finally, the last Amharic version of the questionnaire was prepared for data collection.

\section{Data quality controls}

Seven diploma and seven BSc degree graduate nurses were employed as data collectors and supervisors, respectively. Different measures were taken in order to assure the quality of the data. A 2-day training was given for data collectors and supervisors on the basic techniques of data collection. Pretest was also done in Enewari district on 31 participants to assess the validity, reliability and the clarity of the tools. Necessary modification was also done on unclear questions after the pretest. The result of the reliability test (Cronbach's alpha) for attitude towards maternal healthcare, knowledge about maternal healthcare, and perceived quality of healthcare was $0.72,0.81$ and 0.8 , respectively. Regular monitoring and supervision of the overall activity was done by the supervisors and principal investigator to check the completeness and the quality of data.

\section{Data management and analysis}

The data were checked for completeness, cleaned, coded and entered into EPI Data then exported to SPSS V.22 for analysis. Descriptive statistics were done and the result was presented with narrations, tables and graphs based on the nature of the variables. Both bivariable and multivariable logistic regression analyses were done. Model fitness was checked by Hosmer and Lemeshow goodness of test which was $p=0.7$. Variables having $p<0.2$ in the bivariable analysis were entered into the multivariable logistic regression analysis to identify the factors significantly associated with the outcome variable. Adjusted OR (AOR) with $95 \%$ CI and $\mathrm{p}<0.05$ during the multivariable analysis were used to identify and measure the strength of the association with the outcome variables.

\section{Consent to participate}

The participants had got clear information about the procedures, risks and benefits of the study. In addition, it was also ensured that participants understood the information provided to decide voluntarily whether they want to participate or not. Written informed consent was obtained from each study participant to ensure their voluntariness for participation in this study. Assent from the parents/guardians were taken for participants aged below 18 years. The privacy and confidentiality of the participants were maintained by using anonymity.

\section{Patient and public involvement}

Before the data collection, we communicated with the district and kebele administrators about the nature of our study. Subsequently, we ensured the full collaboration and cooperation of the district and the local administration. We interviewed the participants after clarifying the benefits and risks of the study and obtaining their permission. 


\section{RESULTS}

\section{Sociodemographic characteristics of the participants}

A total of 614 child birth women participated with a response rate of $99 \%$. More than half $(60.7 \%)$ of the respondents aged 25-34 years old with the median age of 30 (8 IQR) years old. More than $90 \%(91.0 \%)$ of the women were married and over $95.8 \%$ were orthodox Christians. One-fifth $(21.2 \%)$ of the women were urban dwellers and more than half $(57.1 \%)$ of the respondents had household monthly income of less than US\$31.26 with a median (IQR) of US\$71.9 (US\$61.58). Nearly three-fourth $(74.1 \%)$ of the mothers and $70.7 \%$ of their husbands had no formal education. Nearly two-thirds $(64.5 \%)$ of the participants and $61.6 \%$ of their husbands were housewives and farmers, respectively (table 1).

\section{Health service access and women's autonomy}

Over two-thirds $(70.5 \%)$ of the respondents accessed health facility after walking of $\geq 30 \mathrm{~min}$ to reach a health facility. Nearly a quarter $(23.6 \%)$ of the women lived less than $5 \mathrm{~km}$ from health facilities. Among all participants, $76.9 \%$ went to a health facility on foot and $57.5 \%$ of the women were members of health insurance. Regarding autonomy, $32.4 \%$ of the women had decided to visit health facilities when they needed by themselves (table 2).

\section{Perception of health service quality}

Of all participants, $351(57.2 \%)$ had poor perception about the quality of healthcare services. Above $95 \%$ of respondents perceived that health facilities had adequate rooms and health professionals. In addition, $340(55.4 \%)$ and $399(65 \%)$ of respondents thought health facilities had no adequate medical equipment and drugs, respectively. More than half of the respondents (54.4\%) perceived that health professionals did not respect patients (table 3 ).

\section{Source of information}

More than half $(54.2 \%)$ of the women had got maternal health-related information from health professionals. The source of information for nearly one-third (31.4\%) and one-fifth (19.4\%) of the participants were also radio and TV, respectively (figure 1 ).

\section{Knowledge of women about maternal healthcare services}

Majority of the respondents $(81.4 \%)$ had poor knowledge about maternal healthcare services. Ninety percent (90.4\%) reported that ANC was needed for mothers, but only $93(15.1 \%)$ of women reported that ANC had started within 4 months of pregnancy. About $1 / 10$ th of respondents knew counting fetal heart beat and eating iron-rich food are important at the last stage of pregnancy and to prevent anaemia, respectively. Nearly all $(98.7 \%)$ of the respondents knew the difference between gave birth at home and health facility, the importance of vaccination and breastfeeding for newborns. Only 36 (5.9\%), $57(9.3 \%)$ and $87(14 \%)$ of them had good knowledge about the time of gestational deformity, what to do when amniotic fluid breaks, and the need for repeated blood pressure examination, respectively (table 4 ).

\section{Attitude towards maternal healthcare services}

More than the three-quarters $(79.2 \%)$ of the respondents had an unfavourable attitude towards maternal healthcare services. Majority of respondents $(93.2 \%)$ agreed with the necessity of ANC, 584 (95.1\%) wanted to breastfeed, and $605(98.5 \%)$ wanted to give birth at a health facility for their next delivery. Few $(11.4 \%)$ of the respondents agreed on returning to work after giving birth and $114(18.6 \%)$ agreed on getting instructions about infant feeding from health workers (table 5).

\section{Obstetric-related characteristics}

Nearly two-thirds $(63.4 \%)$ of the women had a history of contraceptive use before they gave birth, and 394 (64.2\%) of the participants responded that they had a desire to have a child. More than one-third $(37.9 \%)$ of participants gave births more than three babies and 263 (42.8\%) of the women had started to initiate their first ANC visit after 4 months gestational age (table 6).

\section{Continuum of maternal healthcare services utilisation} Antenatal care

Over half $(58.3 \%)$ with (95\% CI 54.4 to 62.1$)$ had first ANC visit and $44.5 \%$ with (95\% CI 40.9 to 48.4 ) had at least four visits (ANC-4) during their recent pregnancy. Nearly all women had got blood pressure measurement, blood sample test, urine test, Tetanus Toxoid (TT) vaccination and HIV test. Three hundred and forty-three (95\%) of the participants had got information about danger signs of pregnancy and iron supplementation (table 7).

\section{Institutional delivery}

Over one-third (43.2\%) with (95\% CI 39.4 to 47.1 ) of mothers gave birth at health institutions. Birth weight for all babies delivered at health institutions was measured. Out of all who gave birth at health institutions, 261 (98.5\%), 254 (95.8\%), $264(99.6 \%), 82(31 \%)$ and $89(33.6 \%)$ had got skin to skin contact their mothers, initiate breastfeed within an hour, babies got vaccinated, counselled about postpartum contraceptive, and postpartum complication, respectively (table 8 ).

\section{Postnatal care}

In this study, $17.8 \%$ (95\% CI $14.8 \%$ to $21.2 \%$ ) of women had received at least one PNC service within 6 weeks after delivery. Over three-fourths women had counselled about when to bath their baby, exclusive breast feeding, a neonatal danger signs, immunisation and checked for vaginal bleeding. On top of that, 78 (71) and $9(8.3 \%)$ women had checked their BP and got iron supplementation, respectively (table 9 ).

Regarding continuum of maternal health services, nearly one-third $(30.8 \%)$ among ANC users gave birth at a health institution. Only $17.8 \%$ of women had also received at least one PNC service within 6 weeks after delivery. As a result, only $16.1 \%$ (95\% CI $13.3 \%$ to $19 \%$ ) of women had received the whole components of continuum of maternal health services (figure 2). 
Table 7 Antenatal care (ANC) service utilisation of participants in Siyadebirena Wayu district, central Ethiopia, 2020

\begin{tabular}{lcc}
\hline Variables & Frequency & $\%$ \\
\hline ANC & & \\
No & 256 & 41.7 \\
Yes & 358 & 58.3 \\
No of ANC visit $(n=358)$ & & \\
1 & 1 & 0.2 \\
$2-3$ & 84 & 13.7 \\
$\geq 4$ & 273 & 44.5 \\
\hline
\end{tabular}

Blood pressure measurement

\begin{tabular}{lrr} 
No & 0 & 0 \\
Yes & 358 & 100 \\
Blood sample test & & \\
\hline No & 1 & 0.3 \\
Yes & 357 & 99.7 \\
\hline Urine test & \\
\hline No & 1 & 0.3 \\
\hline Yes & 357 & 99.7 \\
\hline HIV test & & \\
\hline No & 1 & 0.3 \\
\hline Yes & 357 & 99.7 \\
\hline TT vaccination & & \\
\hline No & 1 & 0.3 \\
\hline Yes & 357 & 99.7 \\
\hline Information about pregnancy danger signs & \\
\hline No & 10 & 2.8 \\
\hline Yes & 348 & 97.2 \\
\hline Iron supplementation & & 4.2 \\
\hline No & 15 & 95.8 \\
\hline Yes & 343 & \\
\hline
\end{tabular}

\section{Factors associated with maternal healthcare services}

We fitted four regression models to identify factors associated with ANC, Institutional delivery, PNC and COC. The output of three regression models that identified the factors of key maternal services (ANC, institutional delivery and $\mathrm{PNC}$ ) utilisation was presented with a single table and the interpretations are stated sequentially. The output of the fourth regression model which specifies the factors of COC was presented in a separate table with its detail interpretation.

In this study, urban residency (AOR 9.0; 95\% CI 3.1 to 25.9), women aged 25-34years (AOR 2.8; 95\% CI 1.2 to 6.3 ), previous history of contraceptive utilisation (AOR 2.0; 95\% CI 1.0 to 3.8), and HH monthly income more than US $\$ 78.15$ (AOR 5.2; 95\% CI 2.1 to 13.0) were positively associated ANC service utilisation. Moreover, urban residency (AOR 4.9; 95\% CI 1.9 to 12.3), women
Table 8 Institutional delivery service utilisation of participants in Siyadebirena Wayu district, central Ethiopia, 2020

\begin{tabular}{|c|c|c|}
\hline Variables & Frequency & $\%$ \\
\hline \multicolumn{3}{|l|}{ Place of delivery } \\
\hline Home & 349 & 56.8 \\
\hline Health facility & 265 & 43.2 \\
\hline \multicolumn{3}{|c|}{ Getting baby's weight measurement $(n=265)$} \\
\hline No & 0 & 0 \\
\hline Yes & 265 & 100 \\
\hline \multicolumn{3}{|c|}{ Exercise skin to skin contact } \\
\hline No & 4 & 1.5 \\
\hline Yes & 261 & 98.5 \\
\hline \multicolumn{3}{|l|}{ Getting cord care } \\
\hline No & 1 & 0.4 \\
\hline Yes & 264 & 99.6 \\
\hline \multicolumn{3}{|c|}{ Getting vaccination for baby } \\
\hline No & 1 & 0.4 \\
\hline Yes & 264 & 99.6 \\
\hline \multicolumn{3}{|c|}{ Getting blood measurement for mothers } \\
\hline No & 1 & 0.4 \\
\hline Yes & 264 & 99.6 \\
\hline \multicolumn{3}{|c|}{ Breast feed initiation within 1 hour after delivery } \\
\hline No & 11 & 4.2 \\
\hline Yes & 254 & 95.8 \\
\hline \multicolumn{3}{|c|}{ Getting counselling about postpartum contraceptive use } \\
\hline No & 183 & 69 \\
\hline Yes & 82 & 31 \\
\hline \multicolumn{3}{|c|}{ Getting counselling about postpartum complications } \\
\hline No & 176 & 66.4 \\
\hline Yes & 89 & 33.6 \\
\hline
\end{tabular}

who lived less than $5 \mathrm{~km}$ (AOR 2.4; 95\% CI 1.1 to 5.2), access to public transport (AOR 2.0; 95\% CI 1.1 to 3.6), previous history of contraceptive use (AOR 2.0; 95\% CI 1.1 to 3.8), and women who gave four or more births (AOR 2.8; 95\% CI 1.2 to 6.6) were also 4.9, 2.4, 2.0,2.0 and 2.8 times more likely delivered in health institutions compared with their counterparts, respectively. Furthermore, urban residency (AOR 5.3; 95\% CI 1.5 to 18.4), access to public transport (AOR 2.3; 95\% CI 1.1 to 4.6), women who had good knowledge (AOR 5.4; 95\% CI 2.0 to 15.3 ) and autonomous women (AOR 3.5; 95\% CI 1.6 to 3.8) were positively associated with PNC service utilisation (table 10).

\section{Factors associated with continuum of maternal healthcare service}

In bivariable logistic regression analysis; age, women educational status, household monthly income, perceived time taken to reach a health facility, perceived 
Table 9 Postnatal care (PNC) service utilisation of participants in Siyadebirena Wayu district, central Ethiopia, 2020

\begin{tabular}{|c|c|c|}
\hline Variables & Frequency & $\%$ \\
\hline \multicolumn{3}{|l|}{ PNC } \\
\hline No & 505 & 82.2 \\
\hline Yes & 109 & 17.8 \\
\hline \multicolumn{3}{|c|}{ Time of PNC visit $(n=109)$} \\
\hline Within 24 hours & 106 & 17.3 \\
\hline $48-72$ hours & 56 & 9.1 \\
\hline $7-14$ hours & 6 & 1.0 \\
\hline$>14$ to 42 days & 2 & 0.3 \\
\hline \multicolumn{3}{|c|}{ Counselled about when to bath the baby } \\
\hline No & 24 & 22 \\
\hline Yes & 85 & 78 \\
\hline \multicolumn{3}{|c|}{ Counselled about exclusive breast feeding } \\
\hline No & 22 & 20.2 \\
\hline Yes & 87 & 79.8 \\
\hline \multicolumn{3}{|c|}{ Counselled about neonatal danger signs } \\
\hline No & 22 & 20.2 \\
\hline Yes & 87 & 79.8 \\
\hline \multicolumn{3}{|c|}{ Counselled about immunisation } \\
\hline No & 22 & 20.2 \\
\hline Yes & 87 & 79.8 \\
\hline \multicolumn{3}{|c|}{ Blood pressure measurement } \\
\hline No & 22 & 20.2 \\
\hline Yes & 87 & 79.8 \\
\hline \multicolumn{3}{|c|}{ Checked vaginal bleeding } \\
\hline No & 22 & 20.2 \\
\hline Yes & 87 & 79.8 \\
\hline \multicolumn{3}{|l|}{ Getting wound care } \\
\hline No & 31 & 28.4 \\
\hline Yes & 78 & 71.6 \\
\hline \multicolumn{3}{|c|}{ Iron and folic acid supplementation } \\
\hline No & 100 & 91.7 \\
\hline Yes & 9 & 8.3 \\
\hline
\end{tabular}

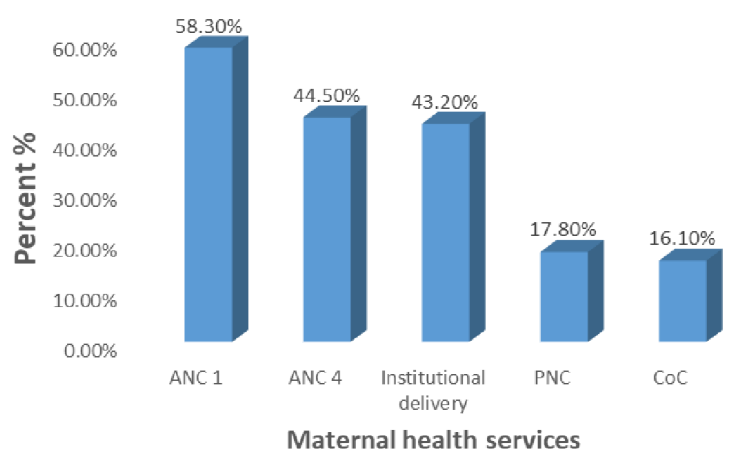

Figure 2 Continuum of maternal health service utilisation in Siyadebirena Wayu district, central Ethiopia, 2020. ANC, antenatal care; CoC, continuum of care; PNC, postnatal care. distance from the health facility, perceived quality of care, autonomy, knowledge on maternal healthcare, attitude towards maternal healthcare, birth order, history of contraceptive use, means of transport, residency and desire for pregnancy had association with the continuum of maternal healthcare service utilisation at $p<0.2$. These variables had been entered to multi-variable logistic regression to determine the statistical significant association of variables with the dependent variable. After performing multivariable logistic regression analysis, knowledge about maternal healthcare, perceived time to reach a health facility, autonomy, history of contraceptive use, residency, women educational status, means of transport and birth order were found to be significantly associated with the continuum of maternal healthcare service utilisation at $\mathrm{p}<0.05$.

Accordingly, women who had good knowledge were 9.88 (AOR 9.88; 95\% CI 3.89 to 25) times more likely to utilise continuum of maternal healthcare service compared with women who had poor knowledge. Women who used public transport to reach at health facilities were 2.48 (AOR 2.48; 95\% CI 1.12 to 5.52) times more likely to use continuum of maternal healthcare than women who went on foot. Women who gave birth to their third child were less likely to use continuum of maternal healthcare by $78 \%$ (AOR 0.22 ; $95 \%$ CI 0.06 to 0.8 ) compared with women who gave birth to their first child. Women who had history of contraceptive use were 4.95 (AOR 4.95; 95\% CI 1.61 to 15.2) times more likely to utilise continuum of maternal healthcare compared with their counterparts. Autonomous women were 4.45 (AOR 4.45 ; $95 \%$ CI 1.69 to 11.6 ) times more likely to utilise continuum of maternal healthcare than non-autonomous women. Women who took less than $30 \mathrm{~min}$ to reach at health facility were 3.17 (AOR 3.17; 95\% CI 1.38 to 7.25 ) times more likely to use continuum of maternal healthcare service compared with women who walked more than $30 \mathrm{~min}$. Secondary and above attended women were 5.36 (AOR 5.36; 95\% CI 1.15 to 25.06) times more likely to utilise continuum of maternal healthcare service compared with women with no formal education. Urban women were 3.91 (AOR 3.91; 95\% CI 1.06 to 14.39) times more likely to utilise continuum of maternal healthcare compared with women who lived in rural areas (table 11).

\section{DISCUSSION}

This study revealed that women who had at least four ANC, institutional delivery and at least one PNC were 44.5, 43.2 and $17.8 \%$, respectively. Moreover, the overall continuum of maternal healthcare service was $16.1 \%$ (95\% CI $13.3 \%$ to $19.0 \%)$. This indicated that those women who had attended four or more ANC might not guarantee for the completion of the remaining maternal healthcare services, such as institutional delivery and PNC utilisation.

This finding was comparable with studies carried out in Kenya $(18 \%)^{15}$ and sub-Sahara Africa countries $(14 \%){ }^{32}$ 


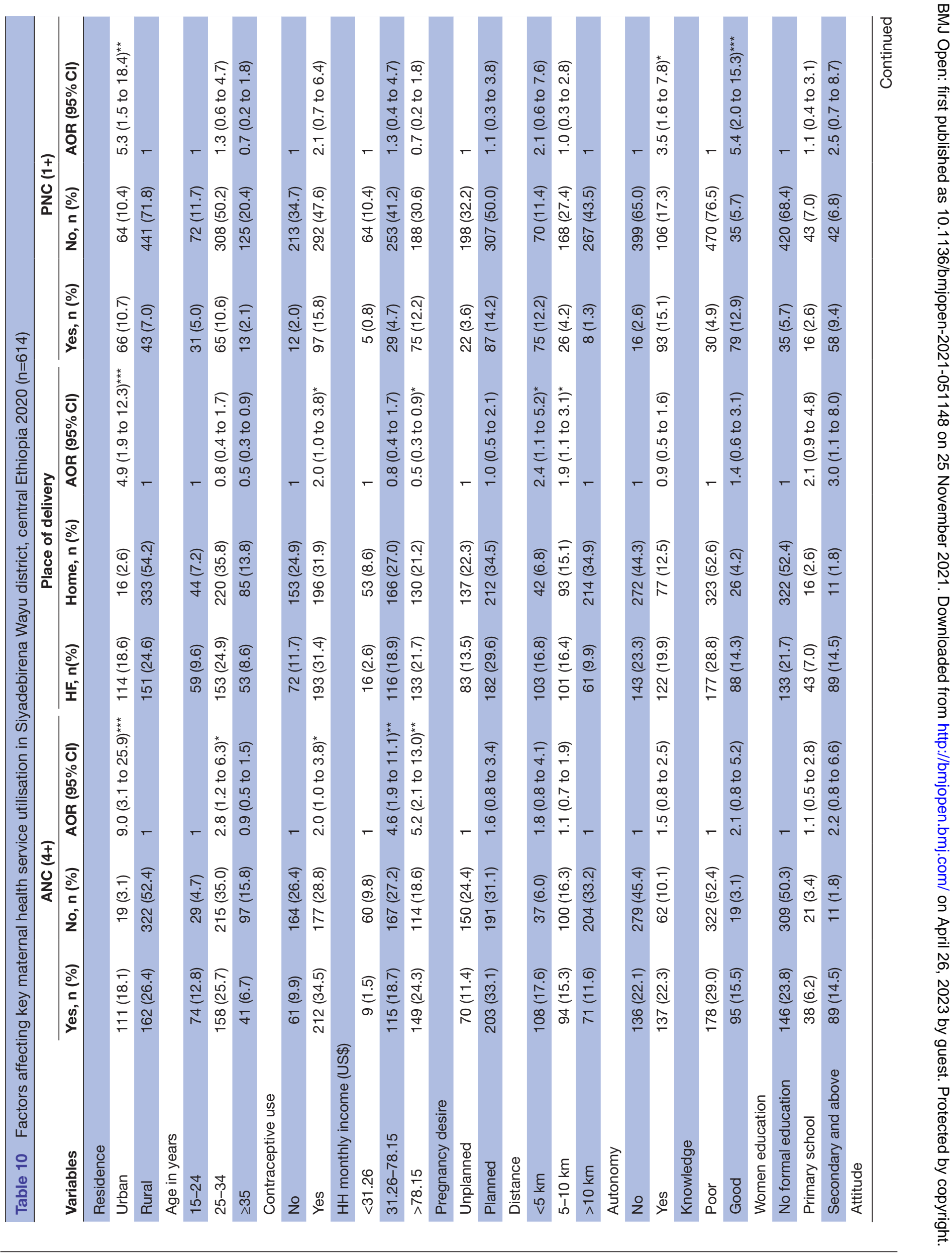




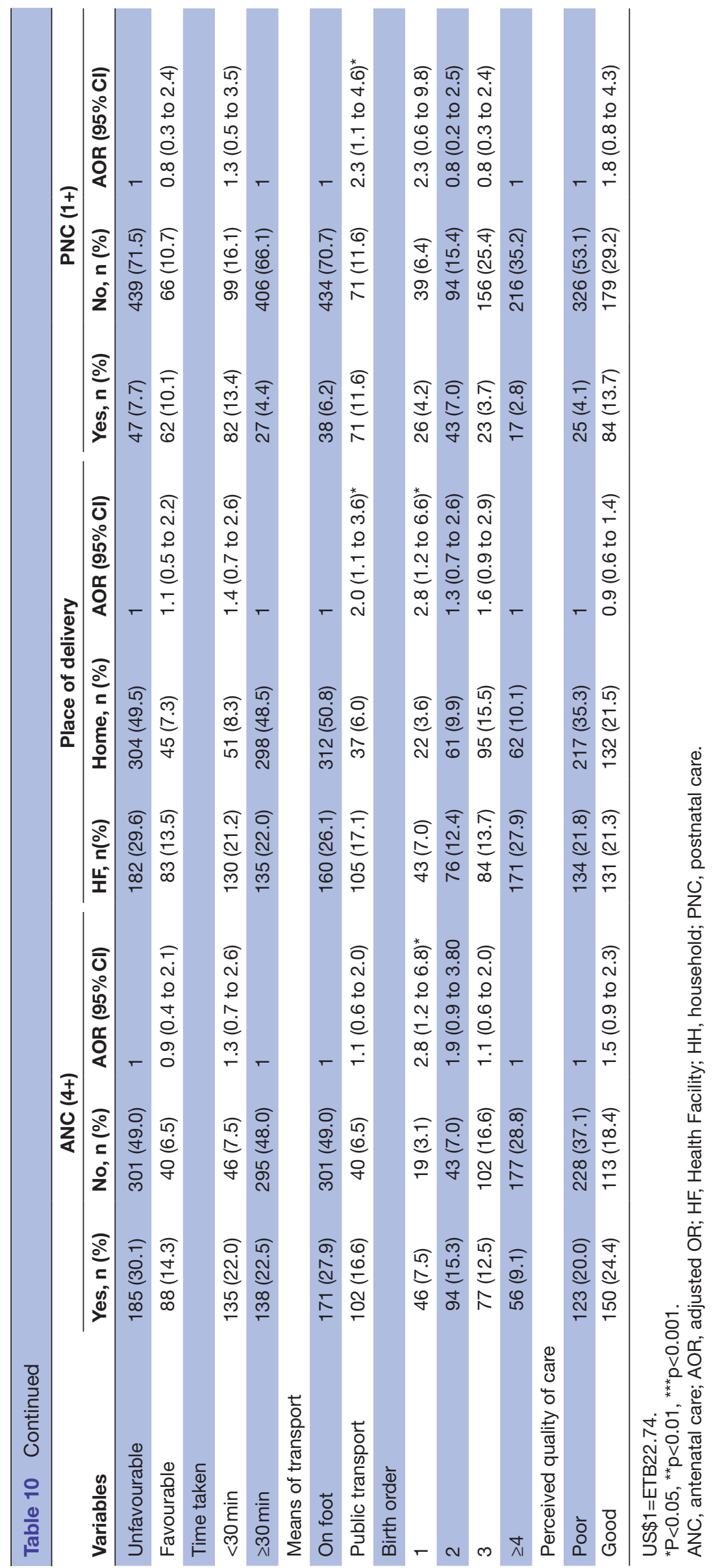


Open access

Table 11 Factors associated with continuum of maternal health service utilisation in Siyadebirena Wayu district, central Ethiopia, $2020(n=614)$

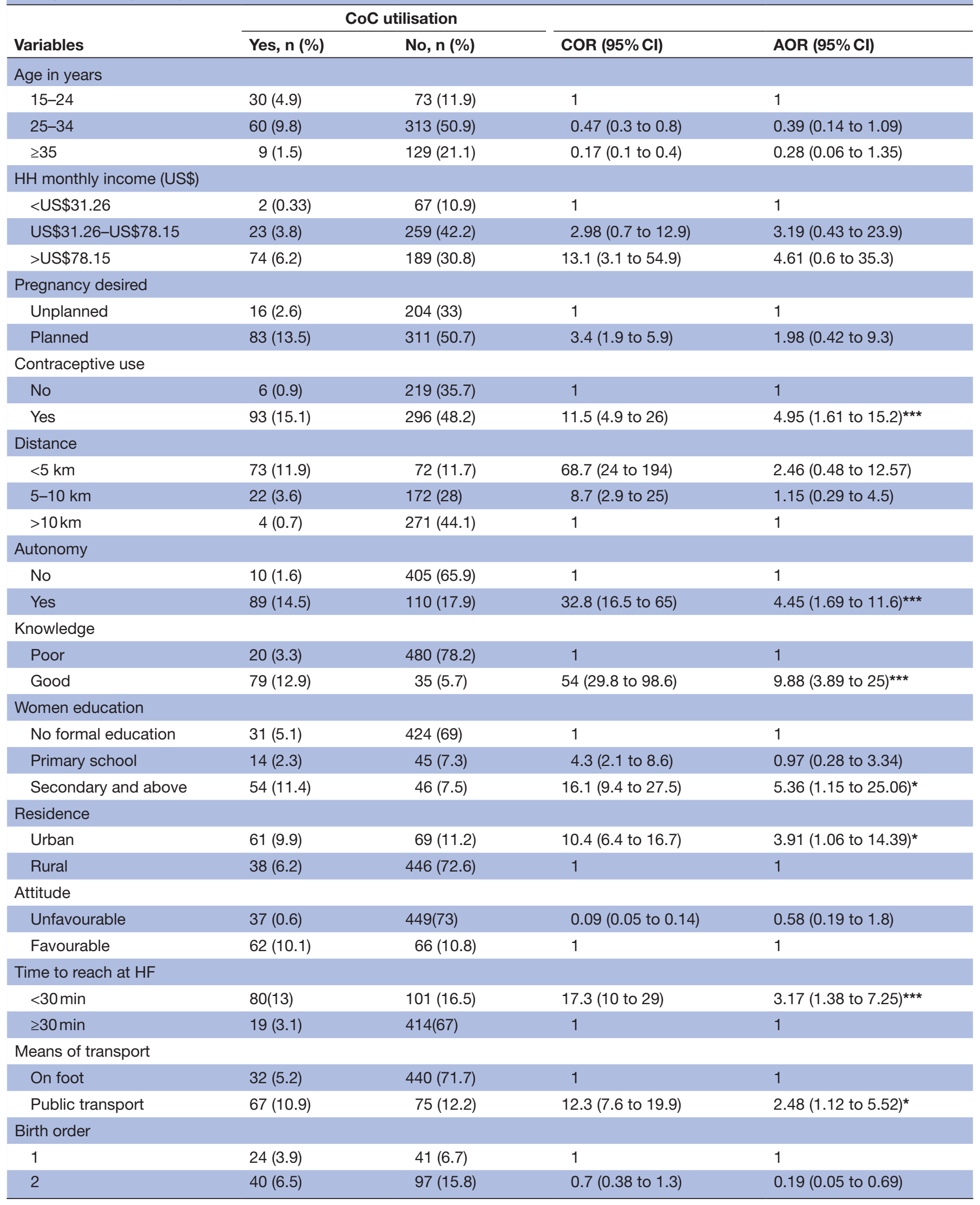

Continued 
Table 11 Continued

\begin{tabular}{|c|c|c|c|c|}
\hline \multirow[b]{2}{*}{ Variables } & \multicolumn{2}{|c|}{ CoC utilisation } & \multirow[b]{2}{*}{ COR $(95 \% \mathrm{Cl})$} & \multirow[b]{2}{*}{ AOR $(95 \% \mathrm{Cl})$} \\
\hline & Yes, n (\%) & No, n (\%) & & \\
\hline 3 & $21(3.4)$ & $158(25.7)$ & $0.28(0.16$ to 0.45$)$ & $0.22(0.06 \text { to } 0.8)^{\star}$ \\
\hline \multicolumn{5}{|c|}{ Perceived QoC } \\
\hline Poor & $19(3.1)$ & $332(54.1)$ & 1 & 1 \\
\hline
\end{tabular}

US\$1=ETB22.74.

${ }^{*} \mathrm{P}<0.05,{ }^{* * *} \mathrm{p}<0.001$

AOR, adjusted OR; CoC, continuum of care; COR, Crude Odds Ratio; HF, Health Facility; HH, household; QoC, quality of care.

However, the finding was slightly higher than studies conducted in Arbaminch (9.7\%), ${ }^{18}$ a multilevel analysis in Ethiopia $(9.1 \%),{ }^{17}$ Ghana $(8 \%)^{13}$ and Tanzania $(10 \%){ }^{14}$ The possible explanation for this difference might be due to the variation in access to health institutions. Women who dwelling in urban and near to the town enable them to access information, and healthcare service utilisation. ${ }^{35}$ The time gap and coverage of a wide geographical area for the multilevel analysis from the Ethiopian Demographic and Health Survey (EDHS) 2016 could be another possible justification. Within these time gap, Ethiopia has been implemented different strategies and advocation for maternal healthcare utilisation. Sociodemographic and methodological differences might also be the other justification for these variations, such as a study conducted in Ghana was predominantly in rural areas. The road network linking for most communities to reach at the district town was bad which hindered access to health facilities. In the contrary, this finding was lower than studies conducted in Egypt (50.4\%), ${ }^{27}$ Cambodia $(60 \%),{ }^{36}$ Pakistan $(27 \%),{ }^{19}$ Nepal $(45.7 \%)^{12}$ and South Asia $(25 \%) .{ }^{16}$ This variation might be due to the differences in socioeconomic status, health service access, and rural-urban discrepancy across the study areas. For example, urbanisation in those study areas might enable women to access health facilities and women education, which, in turn, increased continuum of maternal care utilisation.

The result of this study showed that being urban dwellers has a significant and positive effect on three (ANC, institutional delivery and PNC) of maternal service utilisation in the three regression models which is supported by previous studies carried out in Ethiopia ${ }^{37}$ and Nigeria. ${ }^{38}$ The possible justification might be due to access to healthcare services in urban areas are better than rural.

Women who had history of contraceptive use more likely to use ANC and institutional delivery compared with their counterparts. This finding was consistent with a study done in Arbaminch, Ethiopia. ${ }^{16}$ The possible reason might be due to women who had history of contraceptive use would have an exposure for health information about the importance of maternal service utilisation.
Women who had access to public transport were more likely to receive institutional delivery and PNC services. This finding was in line with a study reported in Ghana. ${ }^{13}$ The possible justification might be because of women who travel long distance on foot might face physical difficulties to reach at health facilities.

Urban dwellers had a better continuum of maternal health service utilisation compared with rural women. This was supported by studies done in Nepal, ${ }^{12}$ South Asia and sub-Sahara Africa, ${ }^{16}$ and a review report in lowincome and middlee-income countries. ${ }^{32}$ The possible justification might be due to women who lived in urban areas might have relatively higher socioeconomic status and better access to both public and private healthcare services. This might be related with an inequitable distribution of healthcare facilities between urban and rural areas. ${ }^{33}$ In the contrary, this finding was contradicted with studies conducted in Ethiopia, ${ }^{17}$ Pakistan $^{19}$ and Cambodia. ${ }^{36}$

Women who had a decision-making autonomy on their own healthcare service utilisation had better COC utilisation compared with non-autonomous women. This was supported by studies carried out in Pakistan, ${ }^{19}$ South Asia and sub-Saharan Africa, ${ }^{16}$ and Nigeria. ${ }^{33}$ This might be due to empowered women might decide on their social and healthcare needs without others influence. Besides, autonomous women might develop self-confidence and abilities to decide on continuity of healthcare services utilisation. $^{37}$

Knowledgeable women were more likely complete maternal healthcare services compared with nonknowledgeable women. The possible justification might be that women who have good knowledge about maternal healthcare would be directly linked to maternal healthcare utilisation since knowledgeable women might have better understanding of their health which contribute to their acceptance and utilisation healthcare services. ${ }^{39}$

Women who walked less than $30 \mathrm{~min}$ to reach at health facility better-utilised COC compared with those women who took more than $30 \mathrm{~min}$. This finding was consistent with studies done in Egypt ${ }^{27}$ and northern Ethiopia. ${ }^{40}$ The possible explanation could be mothers who have longer travelling time might be tired which might be associated 
with their long distance travelling and this made women to be bored.

Secondary and above educated women were more likely to use maternal healthcare service utilisation. This finding was consistent with studies conducted in Pakistan, ${ }^{19}$ Lao, ${ }^{4}$ Nepal, ${ }^{12}$ Egypt,${ }^{27}$ South Asia and sub-Saharan Africa. ${ }^{16}$ This might be due to education could influence women's overall empowerment, access to information and financial freedom to support themselves to take transport, receive quality healthcare services, pay for services and easily absorb healthcare messages by mass media and health professionals. Education might also more empower women on the decision-making process in household issues including utilisation of health services. ${ }^{29} 33$

Women who were using contraceptive methods had a better continuum of maternal service utilisation compared with women who did not use. This finding was in line with a study conducted in Arbaminch zuria district. ${ }^{18}$ The possible justification might be that women who utilised prepregnancy contraception were familiar with the health facility environment and well informed about subsequent maternal and newborn services.

Women who accessed public transport had better completion of maternal health services compared with those who travelled on foot. This finding was consistent with the study done in Ghana. ${ }^{13}$ The possible justification might be women who travelled long distances on foot might face physical difficulties to reach at health facilities. Travelling on foot to health facilities for receiving maternal healthcare could be difficult and transportation might also expensive to rural women. ${ }^{13}$

Women who had only one birth had also a better utilisation of maternal healthcare service. This was consistent with the study carried out in Egypt, ${ }^{27}$ Pakistan, ${ }^{19}$ sub-Saharan Africa. ${ }^{41}$ The possible explanation might be due to the fact that women who gave birth before may have trouble access to childcare. This perhaps would simplify the consequences of pregnancy associated with delivery and may not be encouraged to use healthcare services. ${ }^{42}{ }^{43}$ Women in their first pregnancy may also be anxious of complications since they had no previous experience of pregnancy. ${ }^{27}$

\section{Strengths and limitations of the study}

Assessing the continuity of key maternal care utilisation is the strength of this study. This study might introduce social desirability bias in relation with its self-reporting nature of the study. Recall bias might also another limitation of this study associated with mothers requested to remember their 1 year ago experience. Moreover, this study could not explore the sociocultural facilitators and inhibitors for completion of maternal healthcare services since it was not supported by a qualitative study.

\section{CONCLUSION}

In this study, continuum of maternal healthcare service utilisation was low. Significant decrement was observed among women who received four or more ANC on completion of the remaining maternal healthcare services, such as institutional delivery and PNC. Place of residence, maternal education, time taken to reach health facility, access to public transport, decision making autonomy of women, women awareness and a history of contraceptive use were the factors affecting continuum of maternal healthcare services. Therefore, empowering women's education and decision-making autonomy had a paramount importance to enhance continuum of maternal healthcare services utilisation. Healthcare programmers and decision-makers had better to physical access of health facilities to improve maternal healthcare services.

Acknowledgements The authors would like to thank the University of Gondar, College of Medicine and Health Sciences, Institute of Public Health for providing the ethical approval. Finally, we are thankful to the Siyadebirena Wayu district health office, study participants, data collectors, and colleagues for their support throughout our work.

Contributors SGS conceived the study, adapt the tool, coordinated the data collection activity, and carried out the statistical analysis. SGS, AD and DMG participated in the design of the study and development of the proposal. DMG and SGS had drafted the manuscript. All authors read, reviewed and approved the final manuscript. On behalf of all authors, DMG will act as guarantor for all content of this work.

Funding The authors have not declared a specific grant for this research from any funding agency in the public, commercial or not-for-profit sectors.

Competing interests None declared.

Patient consent for publication Consent obtained directly from patient(s)

Ethics approval Ethical approval of the procedure (Ref. No. IPH/837/6/2012 E.C.) was obtained from the Research Review Board of the Institute of Public Health at the University of Gondar. Besides, a support letter was issued by the Siyadebirena Wayu district health office.

Provenance and peer review Not commissioned; externally peer reviewed.

Data availability statement Data are available on reasonable request. All data relevant to the study are included in the article or uploaded as online supplemental information.

Supplemental material This content has been supplied by the author(s). It has not been vetted by BMJ Publishing Group Limited (BMJ) and may not have been peer-reviewed. Any opinions or recommendations discussed are solely those of the author(s) and are not endorsed by BMJ. BMJ disclaims all liability and responsibility arising from any reliance placed on the content. Where the content includes any translated material, BMJ does not warrant the accuracy and reliability of the translations (including but not limited to local regulations, clinical guidelines, terminology, drug names and drug dosages), and is not responsible for any error and/or omissions arising from translation and adaptation or otherwise.

Open access This is an open access article distributed in accordance with the Creative Commons Attribution Non Commercial (CC BY-NC 4.0) license, which permits others to distribute, remix, adapt, build upon this work non-commercially, and license their derivative works on different terms, provided the original work is properly cited, appropriate credit is given, any changes made indicated, and the use is non-commercial. See: http://creativecommons.org/licenses/by-nc/4.0/.

ORCID iDs

Ayal Debie http://orcid.org/0000-0002-5596-8401

Demiss Mulatu Geberu http://orcid.org/0000-0001-5737-0457

\section{REFERENCES}

1 CSA. Ethiopian demographic health survey key indicators report, 2016.

2 World Health Organization. Trends in maternal mortality 2000 to 2017: estimates by WHO, UNICEF. UNFPA, World Bank Group and the United Nations Population Division, 2019. 
3 Say L, Chou D, Gemmill A, et al. Global causes of maternal death: a who systematic analysis. Lancet Glob Health 2014;2:e323-33.

4 Sakuma S, Yasuoka J, Phongluxa K, et al. Determinants of continuum of care for maternal, newborn, and child health services in rural Khammouane, Lao PDR. PLoS One 2019;14:e0215635.

5 Althabe F, Moore JL, Gibbons L, et al. Adverse maternal and perinatal outcomes in adolescent pregnancies: The Global Network's Maternal Newborn Health Registry study. Reprod Health 2015;12:S8.

6 Thorsteinsdottir H, Bell JM, Bandyopadhyay N. Innovating for maternal and child health in Africa: a mid-term formative evaluation, 2018.

7 Black RE, Morris SS, Bryce J. Where and why are 10 million children dying every year? Lancet 2003;361:2226-34.

8 Van Lerberghe W. The world health report 2005: make every mother and child count. World Health Organization, 2005.

9 Li XF, Fortney JA, Kotelchuck M, et al. The postpartum period: the key to maternal mortality. International Journal of Gynecology \& Obstetrics 1996;54:1-10.

10 Kerber KJ, de Graft-Johnson JE, Bhutta ZA, et al. Continuum of care for maternal, newborn, and child health: from slogan to service delivery. The Lancet 2007;370:1358-69.

11 lqbal S, Maqsood S, Zakar R, et al. Continuum of care in maternal, newborn and child health in Pakistan: analysis of trends and determinants from 2006 to 2012. BMC Health Serv Res 2017;17:189.

12 Tamang TM. Factors associated with completion of continuum of care for maternal health in Nepal, 2017.

13 Yeji F, Shibanuma A, Oduro A, et al. Continuum of care in a maternal, newborn and child health program in Ghana: low completion rate and multiple obstacle factors. PLoS One 2015;10:e0142849.

14 Mohan D, LeFevre AE, George A, et al. Analysis of dropout across the continuum of maternal health care in Tanzania: findings from a cross-sectional household survey. Health Policy Plan 2017;32:791-9.

15 Mwangi W, Gachuno O, Desai M, et al. Uptake of skilled attendance along the continuum of care in rural Western Kenya: selected analysis from global health Initiative survey-2012. BMC Pregnancy Childbirth 2018;18:175.

16 Singh K, Story WT, Moran AC. Assessing the continuum of care pathway for maternal health in South Asia and sub-Saharan Africa. Matern Child Health J 2016;20:281-9.

17 Chaka EE, Parsaeian M, Majdzadeh R. Factors associated with the completion of the continuum of care for maternal, newborn, and child health services in Ethiopia. multilevel model analysis. Int J Prev Med 2019;10:136.

18 Haile D, Kondale M, Andarge E, et al. Level of completion along continuum of care for maternal and newborn health services and factors associated with it among women in Arba Minch Zuria woreda, Gamo zone, southern Ethiopia: a community based cross-sectional study. PLoS One 2020;15:e221670.

19 lqbal S, Maqsood S, Zakar R, et al. Continuum of care in maternal, newborn and child health in Pakistan: analysis of trends and determinants from 2006 to 2012. BMC Health Serv Res 2017;17:189.

20 Boudreaux C, Chanthala P, Lindelow M, . Assessing the elimination of user fees for delivery services in Laos. PLoS One 2014;9:e89784.

21 Ganaba R, llboudo PGC, Cresswell JA, et al. The obstetric care subsidy policy in Burkina Faso: what are the effects after five years of implementation? findings of a complex evaluation. BMC Pregnancy Childbirth 2016;16:84.

22 Witter S, Khadka S, Nath $\mathrm{H}$, et al. The National free delivery policy in Nepal: early evidence of its effects on health facilities. Health Policy Plan 2011;26 Suppl 2:ii84-91.
23 Seki RP, Hendrie D, Daire J, JJBo D. Evaluation of policies for free maternal healthcare in low/middle-income countries: a scoping review protocol. BMJ Open 2019;9:e031557.

24 Wang W, Hong R. Completing the continuum of care for maternal and newborn Heath in Cambodia: who drops out? ICF International, 2013.

25 Centeral Stastical Authority. Population and housing census of Ethiopia. Addis Ababa: Central Statistics Authority, 2007.

26 Federal Democratic Republic of Ethiopia Population Census Commission \%J Addis Ababa ECSA. Summary and statistical report of the 2007 population and housing census, 2008.

27 Hamed A, Mohamed E, Sabry M. Egyptian status of continuum of care for maternal, newborn, and child health: Sohag Governorate as an example. Int J Med Sci Public Health 2018;7:1-27.

28 Kikuchi K, Yasuoka J, Nanishi K, et al. Postnatal care could be the key to improving the continuum of care in maternal and child health in Ratanakiri, Cambodia. PLoS One 2018;13:e0198829.

29 Zhao Q, Kulane A, Gao Y, et al. Knowledge and attitude on maternal health care among rural-to-urban migrant women in Shanghai, China. BMC Womens Health 2009;9:5

30 EDHS EDJKir. Health survey, 2016.

31 van Duong D, Binns CW, Lee AH, et al. Measuring client-perceived quality of maternity services in rural Vietnam. Int J Qual Health Care 2004;16:447-52.

32 Zelka MA, AWJIloSJ Y. Magnitude and determinant of continuum of care in maternal health services and its impact on maternal and infant health outcome. Rev Literature 2019;3:756-69.

33 Dahiru T, Oche OM, OMJPAmj O. Determinants of antenatal care, institutional delivery and postnatal care services utilization in Nigeria. Pan Afr Med J 2015;21.

34 Narang RJljohcqa. Measuring perceived quality of health care services in India, 2010

35 Atnafu A, Kebede A, Misganaw B, et al. Determinants of the continuum of maternal healthcare services in Northwest Ethiopia: findings from the primary health care project. J Pregnancy 2020;2020:1-8.

36 Wang W, Hong R. Levels and determinants of continuum of care for maternal and newborn health in Cambodia-evidence from a population-based survey. BMC Pregnancy Childbirth 2015;15:62.

37 Mekonnen Y, Mekonnen A. Factors influencing the use of maternal healthcare services in Ethiopia. J Health Popul Nutr 2003;21:374-82.

38 Dahiru T, Oche OM. Determinants of antenatal care, institutional delivery and postnatal care services utilization in Nigeria. Pan Afr Med J 2015;21:321.

39 Kaddour A, Hafez R, Zurayk H. Women's perceptions of reproductive health in three communities around Beirut, Lebanon. Reprod Health Matters 2005;13:34-42.

40 Aregay A, Alemayehu M, Assefa $\mathrm{H}$. Factors associated with maternal health care services in Enderta district, Tigray, Northern Ethiopia: a cross sectional study. AJNS 2014;3:117-25.

41 Owili PO, Muga MA, Chou Y-J, et al. Associations in the continuum of care for maternal, newborn and child health: a population-based study of 12 sub-Saharan Africa countries. BMC Public Health 2016;16:414.

42 Gupta S, Yamada G, Mpembeni R, et al. Factors associated with fou or more antenatal care visits and its decline among pregnant women in Tanzania between 1999 and 2010. PLoS One 2014;9:e101893.

43 Mathole T, Lindmark G, Majoko F, et al. A qualitative study of women's perspectives of antenatal care in a rural area of Zimbabwe. Midwifery 2004;20:122-32. 